\title{
Managing Consumer Behaviour through Social Communications
}

\author{
NATALIA ZYKUN ${ }^{1}$, YANA ZOSKA ${ }^{2}$, VILENA VORONOVA ${ }^{3}$, DIANA FAYVISHENKO ${ }^{4}$, \\ YULIIA KYIASHKO ${ }^{1}$, ALINA KUMACHOVA ${ }^{5}$ \\ ${ }^{1}$ Department of Journalism, Ukrainian Literature and Culture, UNIVERSITY OF STATE FISCAL SERVICE OF \\ UKRAINE. UKRAINE \\ ${ }^{2}$ Department of Sociology and Social Work, CLASSICAL PRIVATE UNIVERSITY, UKRAINE. E-mail: zoska@i.ua \\ ${ }^{3}$ Department of Public Relations and Journalism, KYIV NATIONAL UNIVERSITY OF CULTURE AND ARTS, UKRAINE \\ ${ }^{4}$ Department of Journalism and Advertising, KYIV NATIONAL UNIVERSITY OF TRADE AND ECONOMICS, UKRAINE \\ ${ }^{5}$ Department of HR Management and Enterprise Economic, DONETSK STATE UNIVERSITY OF MANAGEMENT, \\ UKRAINE
}

\begin{abstract}
The article examines the issues of using social communications as an integral part of marketing technologies for managing and modifying consumer behaviour. The motivating determinants influencing the formation of consumer behaviour are analyzed; the current role of communications in the field of marketing technologies is considered.

The communication process itself is considered both from a socio-psychological point of view and from the standpoint of the effectiveness of using marketing tools. The points of influence of social communications on consumer decision-making processes have been determined. The article also proposes a methodology for the complex formation and use of social communications as a composite tool for managing and influencing consumers.

In practice, an example of the implementation of this technique has been analyzed, in case of the need to increase the loyalty of customers of an unprofitable company that has encountered difficulties in expanding its customer base and the need to transform the negative opinion of consumers about their own brand.
\end{abstract}

Keywords: consumer behaviour, management influence, social communications, brand loyalty.

JEL Classification: E71, P46, C31, D71, D91

Recibido: 11 de Marzo de 2021

Aceptado:23 de Marzo de 2021 


\section{Introduction.}

Most of the modern marketing strategies, formed by companies, to one degree or another are based on the methodologies of analysis and management of consumer behaviour [1; 3; 6]. The rapid development of modern society, the massive computerization of various spheres of human activity, the deep penetration of information technologies into all aspects of contemporary life, all these factors lead to the fact that the significance of research and analysis of consumer behaviour is significantly increasing [5].

The rapid development of modern economic systems, with a traceable trend towards globalization in various market sectors, emphasizes the need for both strengthening the competitive advantages of market participants and finding effective methods of fighting for consumers. The consumer acts as a critical object around which a marketing company is built; his role becomes dominant in the system of relations between participants in the commodity-money exchange of the consumer sector of the market. It is in light of this that the methods of studying and managing consumer behaviour acquire particular importance.

It should be noted that consumer decisions are influenced by a whole range of different determinants (factors) because consumers do not make their decisions in a vacuum. Determinants of the cultural, social, personal, psychological and economic order, the diagram of which is shown in Fig.1, have a significant influence on the actions performed.

Figure 1. Determinants of consumer behaviour

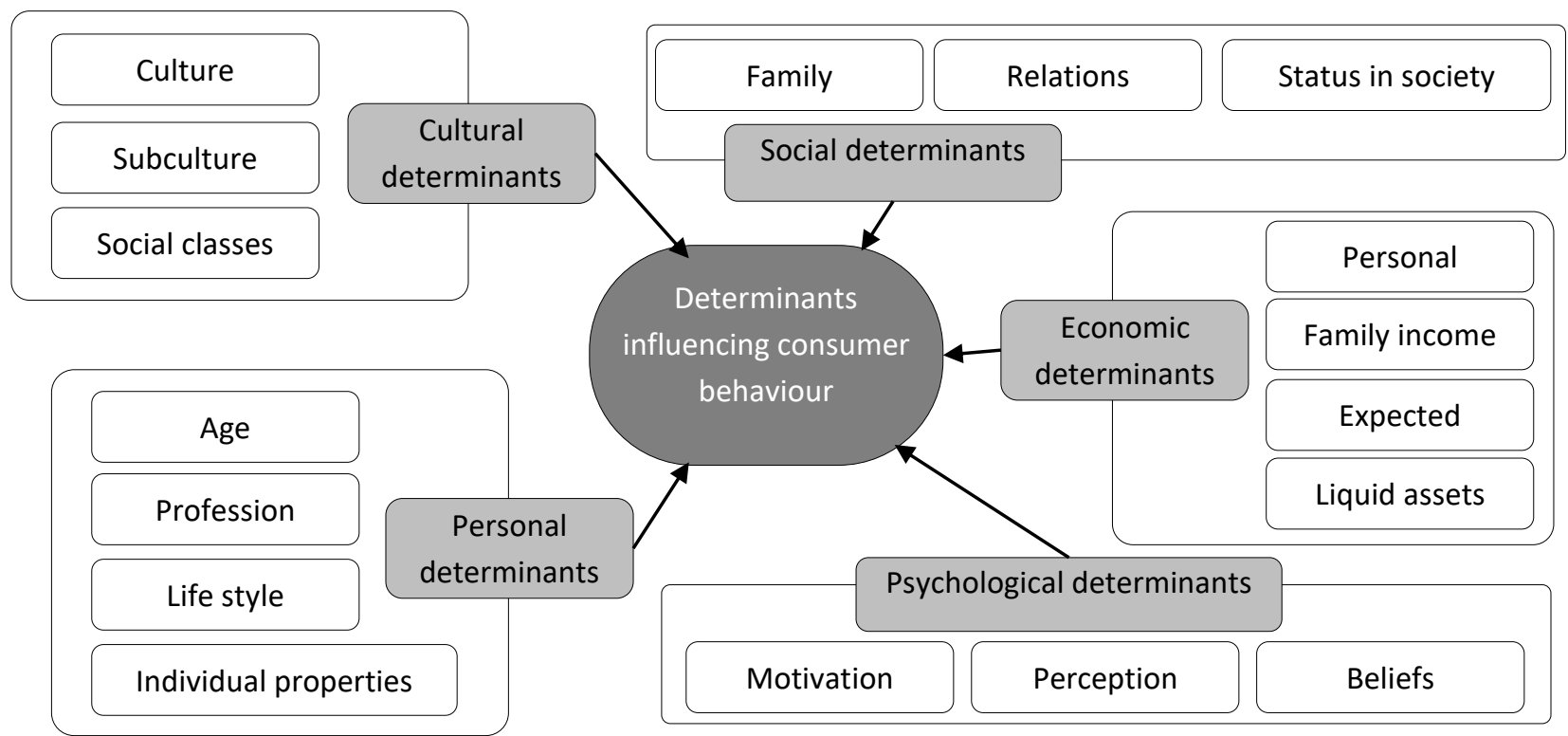

Source: Research findings

Based on the principle of determinism in psychology, consumer behaviour must be considered as a result of the interaction of the inner (mental) world of the individual with external conditions and circumstances. Individual consciousness in this interaction, acting as a sphere of the psychic world of the individual, most significantly determines behaviour. Internal personal causes of behaviour correlate with the accumulated experience and knowledge gained by the individual. In turn, social communications are a tool that can transform and modify, personal determinants that affect consumer behaviour. 


\section{Methodology.}

\subsection{The place and role of social communications among marketing tools for consumer behaviour management.}

Social communications, from the standpoint of managing consumer behaviour, is a process during which information is exchanged, leading to both the transformation of the world perception and the modification of the existing experience and knowledge of a person.

The communication process usually has a two-sided character and involves the implementation of several sequential stages of the formation, transmission, reception, decoding and use of information, the relationship diagram of which is shown in Fig. $2[2 ; 8]$.

Figure 2. Communication chain stages

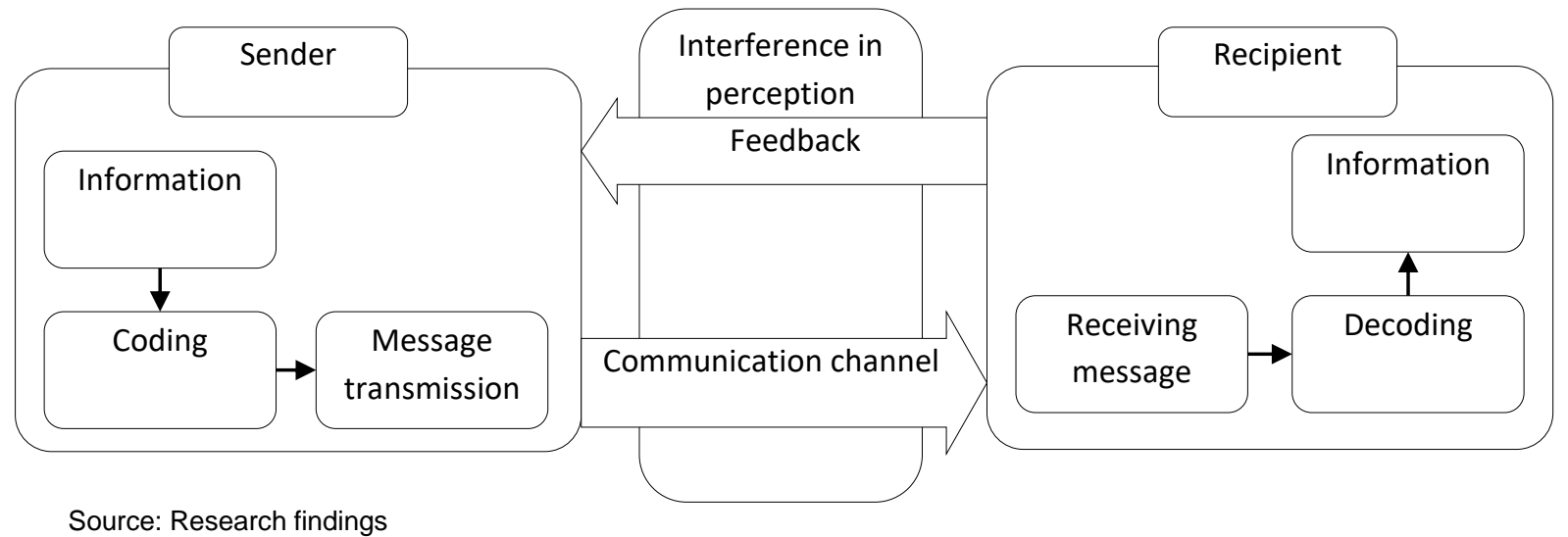

Communication processes allow you to model and manage specific consumer behaviour in the market. The process of social communication consists in the transmission of an information message, while the critical potential stumbling blocks that reduce the effectiveness of the communication process are the stages of encoding and decoding information, as well as the so-called "interference" in information channels. The information encoded in the wrong form of an informational message can be decoded incorrectly as well, and of course, the message by the recipient will be interpreted as in the game "spoiled phone" - far from the meaning that the sender intended. Interference to the information transmission channel is primarily associated with the imperfection of interpersonal communication, and the peculiarities of the human structure, when part of the information may be lost during the transmission.

From marketing, as a methodology for managing consumer behaviour, social communications in the modern economic space are a system of tools, techniques and technologies that provide the formation and transmission of signals and messages about the promoted ideas, goods or services of the target audience and catch the response of the latter to them. The use of social communications to influence consumer behaviour is possible at different levels and using various marketing tools, some of which are presented in Fig. 3.

It is worth noting that social communications have the strongest influence on consumer behaviour at all stages of the direct selling process; their effectiveness, in this case, is manifested in the ability to achieve a preference for a product and encourage a potential consumer to purchase. On the other hand, advertising, public relations and promotion of sales of targeted products have an impact in the long term, in one way or another, influencing consumer loyalty to the company's brand.

The use of social communications makes marketing tools interactive, requiring the expansion of forms of interaction aimed at the formation of strategically beneficial consumer behaviour, the development of relationships and the building of a verified dialogue, by modifying the managerial 
influence on consumer behaviour, from one-way to the development of bilateral sustainable relationships and willingness to cooperate.

Figure 3. Social communications as part of composite marketing tools

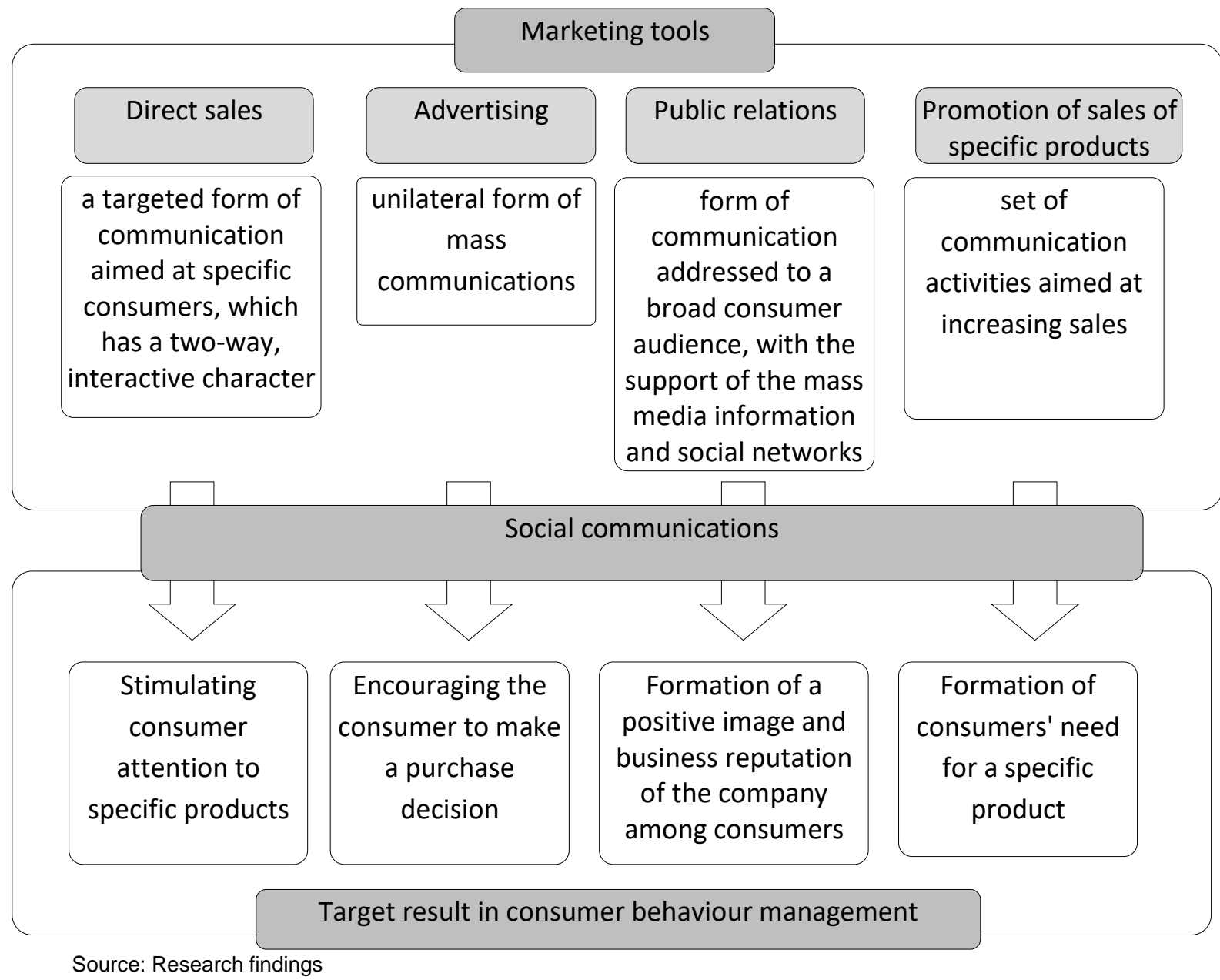

In modern socio-economic realities, social communications, in marketing tools, have acquired a number of prominent features [6]:

- communication relations have developed a more targeted and personalized character;

- communication between the company and consumers has become as individualized as possible;

- the variety of communication channels leads to the complication of the process of their systematization and structuring;

- communications are becoming more and more interactive, that is, there is a tendency to increase the desire of companies to receive the most informative feedback from consumers;

- the tendency towards a decrease in the effectiveness of mass advertising has led to an increase in the synergistic effect from the use of social communications when using individualized advertising means;

- consumer behaviour has changed concerning sources of information about goods; advertising has become perceived as a permanent irritant;

- consumer behaviour has changed in terms of the perception of the product and information about it, personal experience and personal opinion about the product, the place of its sale, and the manufacturer have an increasing influence on the consumer.

Taking these factors into account, the role of social communications in terms of influencing the formation and management of consumer behaviour should focus on three key aspects: 
- cognitive or informational - the dissemination of information about the company, product and its qualities, etc., leading to the expansion of consumer knowledge;

- emotional - creating an impression of the company and its brand among the consumer, forming an appropriate personal attitude, as well as removing dissonant feelings after purchasing a product;

- behavioural - stimulating the consumer's decision to purchase a product, encouraging and approving his actions.

Hence, it is evident that for the effective promotion of the product, supported by the communication relationship between the seller and the buyer (through the transfer of information and receipt of feedback), the informational role-playing aspect of communication is not enough. The behavioural element, based on the emotional perception of the communication addressed to him by the consumer, becomes more critical, transforming this perception into the fact of making a purchase [7].

The impact of social communications on the transformation of consumer behaviour is presented in Fig. 4.

Considering this scheme in more detail, it should be noted that, first of all, the area of involvement of marketing technologies, conditionally characterizes the coverage of the entire environment of the consumer market, it is here that the company's marketing policy is implemented and the range of selected marketing tools is used. The scope of social communications, entering the content of marketing technologies, in turn, is focused on the consumer, and on the formation of his appropriate behaviour. In turn, the formation of consumer behaviour from the consumer himself is based on his basic needs, passing along the chain from the emergence of a need to the stage of implementation by the consumer of actions to meet this need. It should be noted that "Motive", "Benefit" and "Stimulus", as concepts of influence, are taken out of this chain since in essence they are formed in the external environment. "Good" - symbolizes the available goods and services available to meet the need. "Stimulus" - is formed under the influence of communication with the use of marketing tools, in turn, "Motive" - is on the verge, on the one hand, between the internal incentives of the consumer, both formed under the influence of his interests, and influencing his actions. On the other hand, the formation of the "Motive" is an immediate marketing task, implemented directly using social communications.

Figure 4. Scope of social communications in the use of marketing technologies

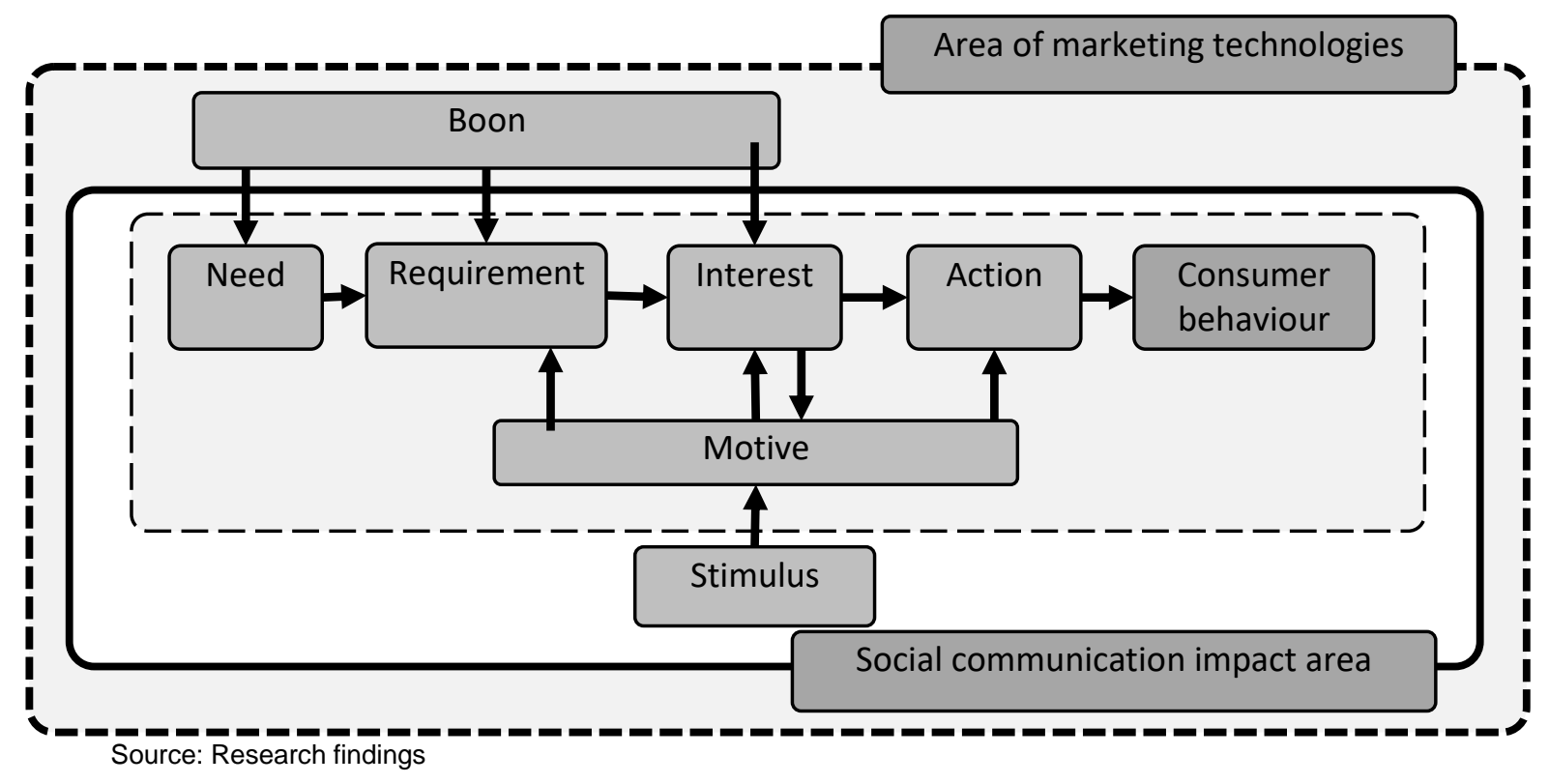




\subsection{Formation of consumer behaviour using social communications.}

It is generally accepted that consumer behaviour, due to the individuality of its manifestation and the autonomy of consumers concerning the company, is little subject to managerial influence and is a constant, formed independently of the marketing efforts of the company and mattered only to analysis [4].

This point of view does not seem so incredible or absurd, but at the same time, consumer behaviour lends itself to effective management, and according to the authors, social communication processes play a significant role in this.

The scheme of interaction, and the formation of an effective, in terms of control and management of consumer behaviour, social communication process, is shown in Fig. 5.

Speaking about the use of social communications to implement a marketing strategy, it should be noted that the use of this mechanism is designed to solve specific target tasks. According to the proposed scheme, they can be divided into four groups:

1) Behavior modification to attract new consumers - the sphere of this group includes communication impact on consumers to perceive the whole brand of the company and its products. In the long term, communication support will drive the behavioural transformation towards building strong brand loyalty.

2) Formation of the perception of consumer satisfaction with the service - from competition for the consumer, it is no longer enough to provide a high-quality service, the use of social communication should be used in order to consolidate the consumer's behaviour, the fact of meeting his resolved need; otherwise the effect of this may be blurred on competing brands. Besides, it is during the implementation of this task that it is possible to receive the most informative feedback from the consumer, which is extremely important in the current conditions, this can only be realized through social communication and overcoming consumer apathy using communication channels.

3) Transformation of consumer behaviour to retain them - this task is supposed to be solved through dialogue, identifying the hidden needs of consumers, forming an information pool of knowledge about consumers, studying preferences and factors that influence consumer loyalty through communication.

4) Communication interaction with consumers to expand the scope of interaction - the task of this group is both to maintain regular communication contact with consumers and to search for ways to expand the areas of business by selling additional goods and services. In the long term, solving this problem will help to strengthen relationships with consumers, increase company loyalty, and increase operating profit.

The very process of forming effective social communication with consumers must necessarily include the following stages:

1) Customer segmentation - we have already mentioned above various factors influencing the formation of consumer behaviour, these determinants combined according to similar features allow us to segment customers into different groups characterized by other behaviour and having exposure to similar methods of communication influence.

2) Determination of the desired parameters of consumer behaviour - for each of the segmented groups it is necessary to understand what kind of "portrait" of behaviour it has and what type of behaviour the company expects from the consumer, so to speak, it is necessary to draw up a "portrait of the ideal consumer."

3) The choice of social communication formats - numerous communication techniques and methods, acceptable and unacceptable forms of communication, strategies and phrases used, various ways of delivering the necessary information - all this is systematized and analyzed to develop company-standardized approaches to social communication with consumers. 
Figure 5. Sequence of stages of the communication process

Tasks solved through social communication

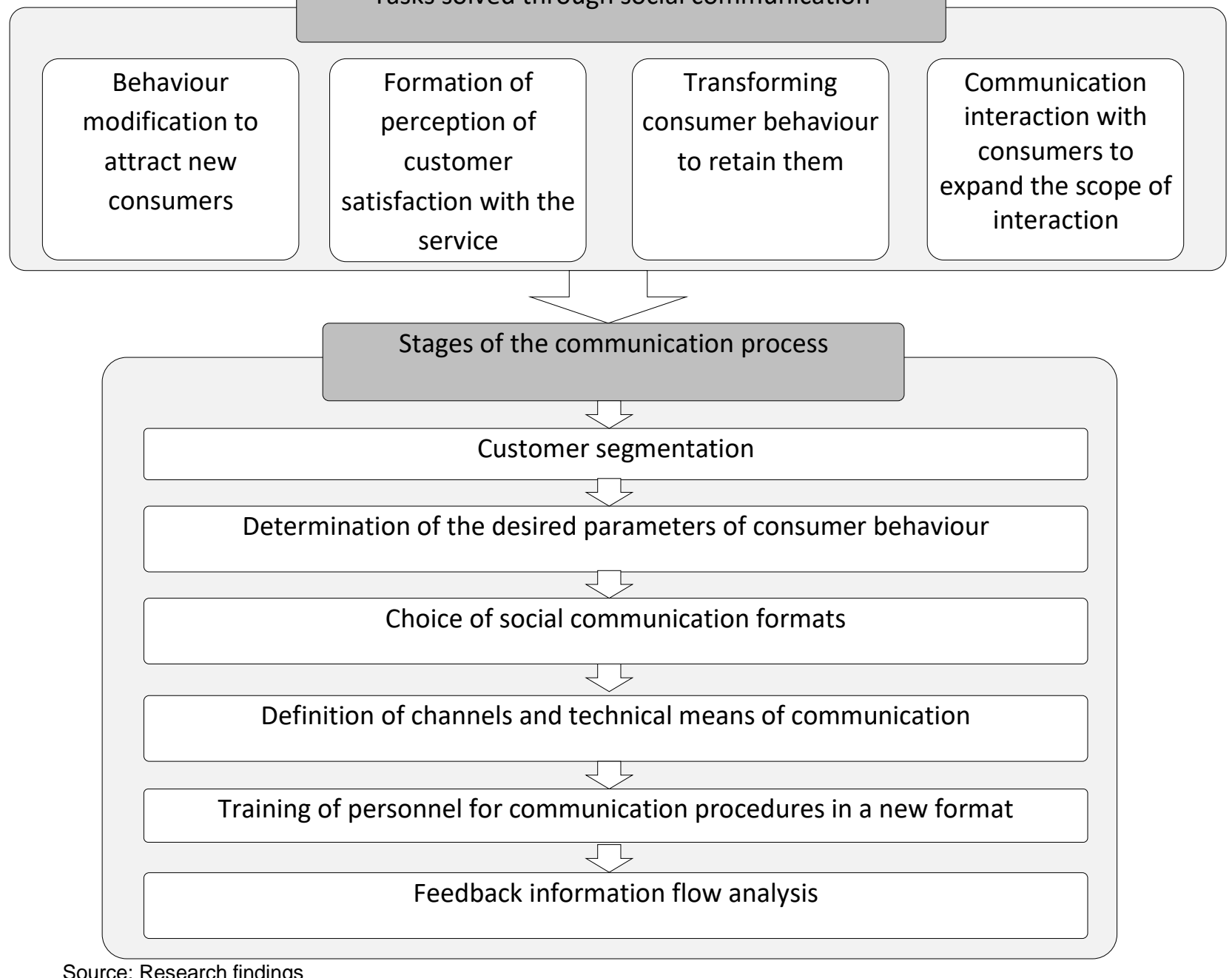

4) Determination of channels and technical means of communication - determination of technical means and channels of acceptable or unacceptable for the implementation of social communication with consumers as part of the company's marketing strategy.

5) Preparing personnel for communication procedures in a new format - defining a set of rules for communication with consumers, conducting training and training personnel according to developed methods of social communication with consumers.

6) Analysis of the feedback information flow - this stage is not final. Still, it only symbolizes the completion of the next iteration of the cycle of formation and implementation of the impact on consumer behaviour within the framework of the company's global strategy. Nevertheless, it should be noted that it is necessary to remove close attention to this stage to avoid unnecessary repetitions and the use of ineffective techniques in subsequent iterations.

The process of implementing the proposed concept of social communication with consumers to form the desired behaviour in the framework of the company's operational activities is shown in Fig. 6.

As can be seen in the presented diagram, the sphere of social communications affects all critical stages of the work of personnel with consumers, as well as how it involves three key aspects informational, motivational and emotional, which were already mentioned above. At the same time, social communication in the context of consumer behaviour management allows achieving the necessary goals through deep integration into operational processes. 


\section{Experiment and analysis of results.}

The basis for the experimental analysis of the effectiveness of using social communication to manage consumer behaviour will be the process of adaptation and implementation based on a company in the field of providing household services to households. The monitoring of the process of changes was carried out by conducting a survey of clients in the period from 2017-2019, the critical point was the determination of changes in behaviour under the influence of the introduction of new methods of work of the company's personnel, taking into account the methodology outlined in the theoretical part.

The survey was conducted by random sampling in the process of working with clients; about 250 consumers were surveyed according to the authors' method [4], the generalized results are presented in Table 1.

The process of implementing the program began in June 2018; at that time, the company was experiencing some difficulties associated with attracting new and retaining existing customers. One of the factors influencing this process was high staff turnover.

Figure 6. Social communication with consumers as part of the company's operational activities

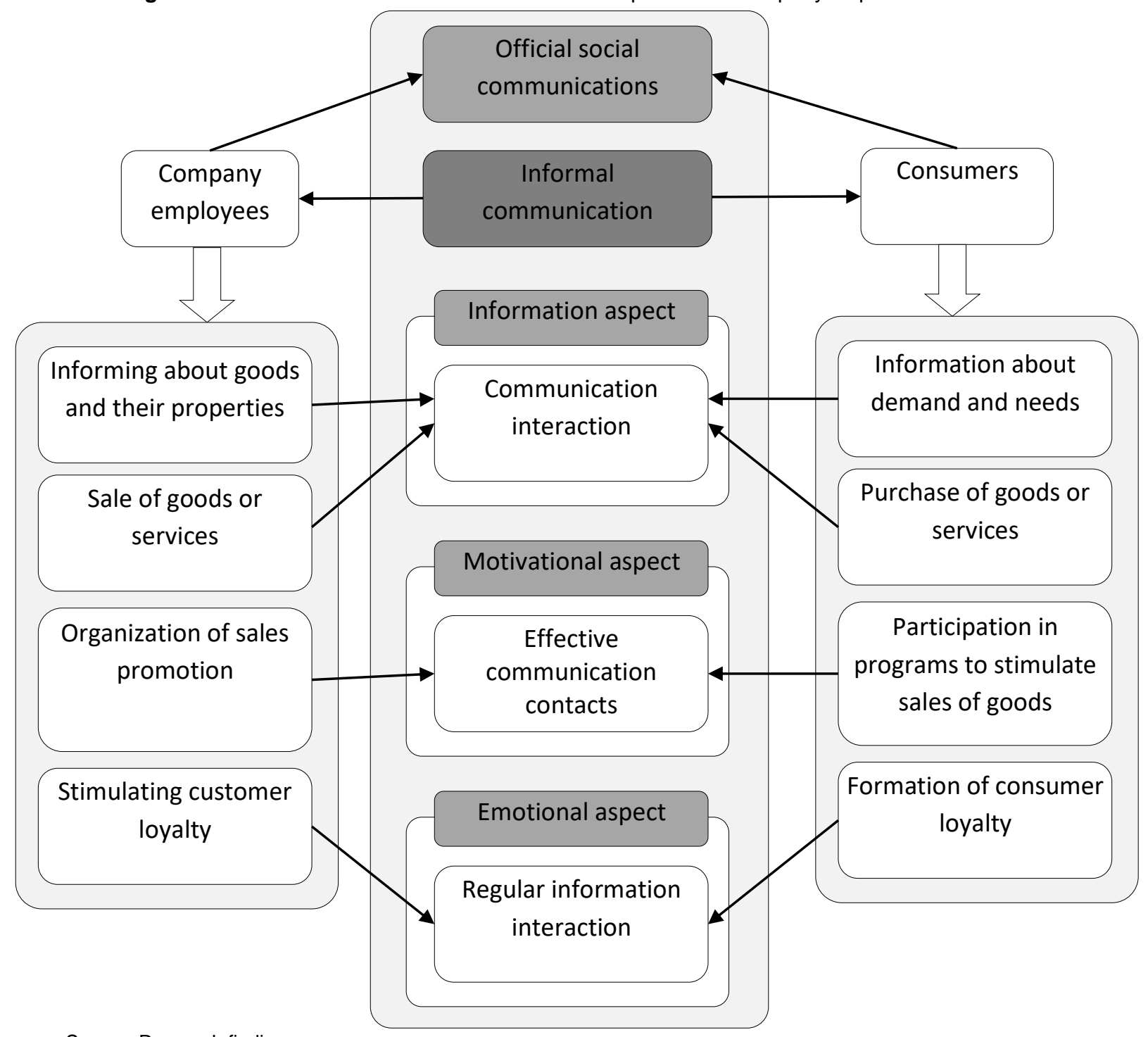

Source: Research findings

The ordered "secret shopper" service revealed several problems associated with the company's business process; in particular, the respondents noted:

- 91\% low readiness of employees for dialogue; 
- $86 \%$ desire to participate in resolving conflict situations:

- $71 \%$ incomplete information about the services provided.

Table 1. Monitoring results in the period from 2017-2019

\begin{tabular}{|c|c|c|c|c|c|c|c|}
\hline & \multirow[b]{2}{*}{ Questionnaire questions } & \multicolumn{2}{|c|}{2017} & \multicolumn{2}{|c|}{2018} & \multicolumn{2}{|c|}{2019} \\
\hline & & $\begin{array}{c}\text { Number of } \\
\text { replies }\end{array}$ & $\begin{array}{l}\text { Percentage } \\
\text { of total }\end{array}$ & $\begin{array}{c}\text { Number of } \\
\text { replies }\end{array}$ & $\begin{array}{l}\text { Percentage } \\
\text { of total }\end{array}$ & $\begin{array}{l}\text { Number } \\
\text { of replies }\end{array}$ & $\begin{array}{l}\text { Percentage } \\
\text { of total }\end{array}$ \\
\hline \multirow[t]{5}{*}{1} & \multicolumn{7}{|c|}{ Indicate the source from which you learned about the company: } \\
\hline & advertising in the media & 32 & $12,8 \%$ & 28 & $11,2 \%$ & 19 & $7,6 \%$ \\
\hline & friends, relatives, significant & 44 & $17,6 \%$ & 46 & $18,4 \%$ & 78 & $31,2 \%$ \\
\hline & the Internet & 32 & $12,8 \%$ & 31 & $12,4 \%$ & 48 & $19,2 \%$ \\
\hline & own previous visit experience & 142 & $56,8 \%$ & 145 & $58,0 \%$ & 105 & $42,0 \%$ \\
\hline \multirow[t]{4}{*}{2} & \multicolumn{7}{|c|}{ Do you have enough information provided by the company about services: } \\
\hline & yes & 89 & $35,6 \%$ & 90 & $36,0 \%$ & 152 & $60,8 \%$ \\
\hline & I find it difficult to answer & 74 & $29,6 \%$ & 71 & $28,4 \%$ & 59 & $23,6 \%$ \\
\hline & no & 87 & $34,8 \%$ & 89 & $35,6 \%$ & 39 & $15,6 \%$ \\
\hline \multirow[t]{5}{*}{3} & \multicolumn{7}{|c|}{ Indicate the most significant source for information on new services available for obtaining: } \\
\hline & $\begin{array}{l}\text { distribution of advertising and } \\
\text { information leaflets; }\end{array}$ & 51 & $20,4 \%$ & 54 & $21,6 \%$ & 24 & $9,6 \%$ \\
\hline & $\begin{array}{l}\text { organization of special } \\
\text { promotional events; }\end{array}$ & 62 & $24,8 \%$ & 66 & $26,4 \%$ & 91 & $36,4 \%$ \\
\hline & $\begin{array}{l}\text { informing by the personal } \\
\text { manager; }\end{array}$ & 66 & $26,4 \%$ & 67 & $26,8 \%$ & 103 & $41,2 \%$ \\
\hline & $\begin{array}{l}\text { sending SMS - messages and e- } \\
\text { mail letters }\end{array}$ & 71 & $28,4 \%$ & 63 & $25,2 \%$ & 32 & $12,8 \%$ \\
\hline \multicolumn{8}{|c|}{ Give your assessment of the quality of communication with the company: } \\
\hline \multirow[t]{4}{*}{4} & \multicolumn{7}{|c|}{ the openness of employees to discuss problems arising in the process of services: } \\
\hline & high & 22 & $8,8 \%$ & 27 & $10,8 \%$ & 153 & $61,2 \%$ \\
\hline & average & 162 & $64,8 \%$ & 168 & $67,2 \%$ & 69 & $27,6 \%$ \\
\hline & low & 66 & $26,4 \%$ & 55 & $22,0 \%$ & 28 & $11,2 \%$ \\
\hline \multirow[t]{4}{*}{5} & \multicolumn{7}{|c|}{ the willingness of workers to compromise conflict resolution: } \\
\hline & high & 37 & $14,8 \%$ & 42 & $16,8 \%$ & 61 & $24,4 \%$ \\
\hline & average & 78 & $31,2 \%$ & 83 & $33,2 \%$ & 98 & $39,2 \%$ \\
\hline & low & 135 & $54,0 \%$ & 125 & $50,0 \%$ & 91 & $36,4 \%$ \\
\hline \multirow[t]{4}{*}{6} & \multicolumn{7}{|c|}{ accessibility and understandability of information transmitted by communications: } \\
\hline & high & 52 & $20,8 \%$ & 57 & $22,8 \%$ & 78 & $31,2 \%$ \\
\hline & average & 97 & $38,8 \%$ & 101 & $40,4 \%$ & 119 & $47,6 \%$ \\
\hline & low & 101 & $40,4 \%$ & 92 & $36,8 \%$ & 53 & $21,2 \%$ \\
\hline \multirow[t]{4}{*}{7} & \multicolumn{7}{|c|}{ completeness of accounting for information obtained when deciding to purchase services: } \\
\hline & high & 72 & $28,8 \%$ & 74 & $29,6 \%$ & 92 & $36,8 \%$ \\
\hline & average & 97 & $38,8 \%$ & 96 & $38,4 \%$ & 91 & $36,4 \%$ \\
\hline & low & 81 & $32,4 \%$ & 80 & $32,0 \%$ & 67 & $26,8 \%$ \\
\hline \multirow[t]{4}{*}{8} & \multicolumn{7}{|c|}{$\begin{array}{l}\text { ability to obtain information about the product and its conditions of use from different } \\
\text { communication channels: }\end{array}$} \\
\hline & high & 85 & $34,0 \%$ & 77 & $30,8 \%$ & 121 & $48,4 \%$ \\
\hline & average & 102 & $40,8 \%$ & 107 & $42,8 \%$ & 87 & $34,8 \%$ \\
\hline & low & 63 & $25,2 \%$ & 66 & $26,4 \%$ & 42 & $16,8 \%$ \\
\hline \multirow[t]{4}{*}{9} & \multicolumn{7}{|c|}{ Give your assessment of satisfaction with the existing communication interaction with the company: } \\
\hline & high & 34 & $13,6 \%$ & 40 & $16,0 \%$ & 84 & $33,6 \%$ \\
\hline & average & 105 & $42,0 \%$ & 101 & $40,4 \%$ & 127 & $50,8 \%$ \\
\hline & low & 111 & $44,4 \%$ & 109 & $43,6 \%$ & 39 & $15,6 \%$ \\
\hline
\end{tabular}

Source: Research findings 
All these factors did not contribute to the formation of the loyalty of existing customers, and also led to a meagre share of recommendations for new ones (only $17 \%$ of respondents used the company's services on the advice of existing customers). Data on the dynamics of changes in loyalty indicators and customer awareness of the company for 2017-2019 are presented in Fig. 7.

Figure 7. Data on changes in loyalty and satisfaction with information among consumers

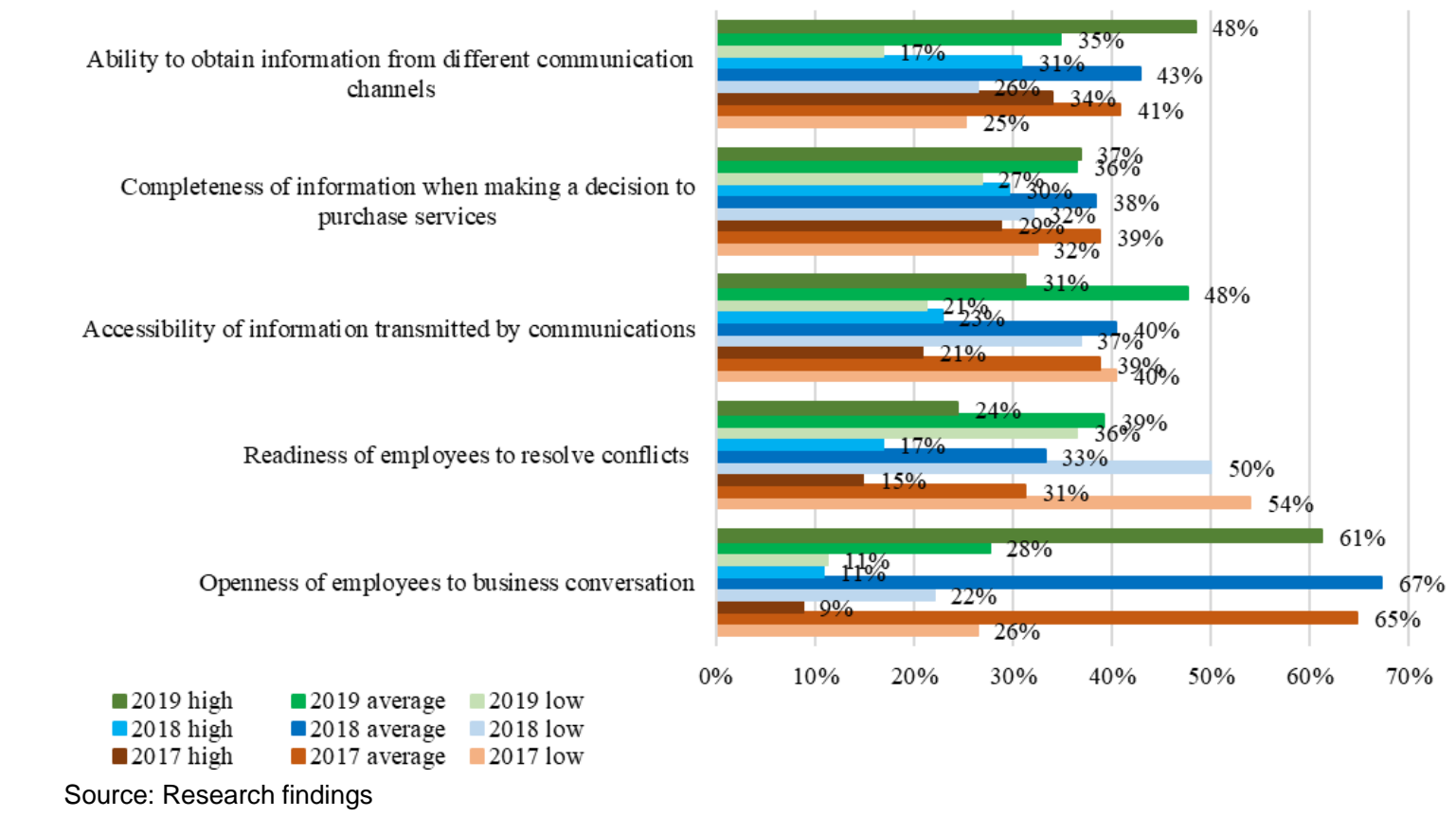

In this situation, the management decided to focus on:

- the decrease in staff turnover;

- teaching new employees the specifics of work;

- training all personnel in the skills of effective communication with clients;

- formation of a set of rules of business ethics for personnel;

- staff motivation for attracting new and retaining existing customers.

Within the framework of the company, from the third quarter of 2018, the "Effective Dialogue" program was launched, using the method of social communication to transform consumer behaviour. The plan was implemented by a third-party consulting program and a training centre, the first stages were carried out in 2 months, then employees underwent monthly one-day training, as well as contacts with the centre's coaches weekly. As part of the program, sets of rules were developed for communicating with existing and new clients of the company, cases for resolving conflict situations were sorted out, training was held to normalize relations with existing clients and maintain a two-way dialogue in the "client-employee" format.

As a result of this, starting from the fourth, a gradual stable increase in the number of clients began to be observed: both due to new and by renewing contracts with previously left clients, the dynamics of changes in the client base is shown in Fig. 8.

By the end of 2019, the following results of the company's work were obtained as part of the program to improve social communication with consumers:

$60 \%$ of surveyed consumers noted the possibility of a business dialogue with company employees (against 10\% in 2018);

$63 \%$ positively assessed the staff's ability to resolve conflict situations (only $50 \%$ in 2018)

$61 \%$ of clients highly rated the quality and completeness of the advice provided (in 2018 this figure was $35 \%)$ 
As a result, loyalty and willingness to recommend the company increased from $17 \%$ in 2018 to $31 \%$ in 2019.

\section{Conclusions.}

Consumer behaviour is a complex process based on various factors that have social, economic, psychological and personal roots. Analysis and management of the formation of consumer behaviour are the basis for the effectiveness of the use of marketing tools, as part of the implementation of the company's global strategy. Social communications are a critical factor that determines both the formation of relationships between the company and consumers and a tool that allows you to modify consumer behaviour. The correct application of social interactions, coupled with traditional marketing mechanisms, can have a powerful synergistic effect that can shape the necessary perception of consumers, those aspects that the company wants to focus on.

\section{References}

1. Balova, S., Firsova, I., \& Osipova, I. (2019). Market leading marketing concepts in the management of consumer behaviour on the energy market. Proceedings of the 3rd International Conference on Social, Economic, and Academic Leadership (ICSEAL 2019), DOI: 10.2991/icseal-19.2019.55

2. Champoux, J. (2020). Communication Processes. Organizational Behavior, DOI: $10.4324 / 9781003000587-20$

3. M. Radhikaashree, M., Devendran, A., \& Sowmya, J. (2018). Trends in Consumers Behaviours towards E-commerce. Eurasian Journal of Analytical Chemistry, 13 (6b), pp. 165-169.

4. Metelenko, N., Ivanenko, L., Kyianytsia, I., Holik, O., Konopliannykova, M., \& Briukhanova, G. (2020). Formation of an Enterprise Strategy Based on Marketing Monitoring of Consumer Behaviour. International Journal of Advanced Research in Engineering and Technology, 11(4), 2020, pp. 427-438.

5. Prokopenko, O., \& Omelyanenko, V. (2018). Marketing aspect of the innovation communications development. Innovative Marketing, 14(2), pp. 41-49.

6. Prokopenko, O.V. (2011). Consumer choice types in marketing of ecological innovations. Actual Problems of Economics, 16(2), pp. 109-116.

7. Puplampu, G., Fenny, A., \& Mensah, G. (2019). Consumers and Consumer Behaviour. Health Service Marketing Management in Africa, DOI: 10.4324/9780429400858-6

8. Pushkar, O., Kurbatova, Y., \& Druhova, O. (2017). Innovative methods of managing consumer behaviour in the economy of impressions, or the experience economy. Economic Annals-XXI, 165(5-6), pp. 114-118 DOI: 10.21003/ea.V165-23

9. Wray, A. (2020). Communication Processes. The Dynamics of Dementia Communication, DOI: 10.1093/oso/9780190917807.003.0007 